Chapter 6

\title{
Thrombophilia in Systemic Lupus Erythematosus: A Review of Multiple Mechanisms and Resultant Clinical Outcomes
}

\author{
Patricia J. Dhar and Robert J. Sokol \\ Additional information is available at the end of the chapter \\ http://dx.doi.org/10.5772/56902
}

\section{Introduction}

Systemic lupus erythematosus, or SLE is a multisystem autoimmune disease that occurs predominantly in African American women of childbearing age, who generally have more severe disease. There are several multi-ethnic global lupus registries ongoing to collect better information on the epidemiology of SLE worldwide [1]. The annual incidence of SLE is 3 cases / 100,000 with prevalence rates reported up to 144/100,000 among the general population [1-2], $90 \%$ of SLE patients being female gender. African Americans and Hispanics as well as males with lupus, general ly have more severe diseases, particularly renal disease, with some studies also showing this association in Asians [1-2]. SLE is a thrombophilic state. Patients with SLErelated hypercoagulability can develop arterial and venous thrombosis as well as intrauterine fetal demise, such as miscarriages and stillbirths. Multiple mechanisms contribute to hypercoagulability in SLE, including lupus specific factors such as antiphospholipid antibodies. These antibodies also contribute to cardiovascular and cerebrovascular disease in lupus. The inflammation in SLE can increase certain procoagulant factors which can tip the balance towards thrombosis. In addition, platelet hyperfunction in SLE promotes thrombogenesis and is particularly important in premature cardiovascular disease management in women with lupus. Thrombogenesis in SLE is best explained by the multiple-hit theory in which several procoagulant or anticoagulant effects occur, which additively can attain the critical overall effect needed to generate a blood clot. Thus, when assessing lupus patients for thrombosis or intrauterine fetal demise, a larger laboratory work up is needed to define the coagulation abnormalities in order to fine tune the most effective anticoagulation regimen as well as determine length of treatment. This chapter will briefly review the clinical syndromes associated with thrombophilic lupus related antibodies, with an emphasis on pregnancy loss, 
cardiovascular disease and clotting, the multiple mechanisms for hypercoagulability in SLE, and discuss the complexity of this problem in this population.

\section{Epidemiology}

\subsection{Vascular thrombosis}

The epidemiology of vascular thrombosis is well described in SLE and with several studies showing an increased risk for arterial and venous thrombosis. Arterial and venous thrombosis occurs in approximately $10 \%$ of SLE patients [3-7] with thrombosis being a major cause of death in patients with lupus [8]. Gender differences have been reported with male SLE patients having a higher prevalence of thrombosis and antiphospholipid antibody syndrome compared to women with lupus [9]. Thrombovascular events occur throughout the course of lupus disease with an increase risk over time [10-11]. Arterial vascular events occur more frequently in post- menopausal women with lupus and are associated with age, disease duration, smoking and mean dose of glucocorticoids [12]. Venous thrombosis is also associated with smoking in lupus [12]. Other risk factors for thrombosis in lupus include high disease activity, lupus nephritis /nephrotic syndrome, elevated homocysteine, and the presence of antiphospholipid antibodies [11, 13-16].

\subsection{Pregnancy loss}

The factors which increase thrombosis risk also promote pregnancy loss in lupus. Patients with SLE have increased frequencies of intrauterine growth restriction and fetal demise (miscarriage and stillbirth) which can predate the diagnosis of lupus [17-18]. Pregnancy complications in SLE are fairly common with maternal hypertensive complications occurring in $10-20 \%$, preterm births in $20 \%$ and fetal growth restriction occurring in about $28 \%$, with an average drop in fetal growth weight to be $16 \%$ [18-19]. Fetal wastage is markedly increased in SLE with stillbirths occurring in $4-22 \%$ and miscarriage rates reported to range from approximately $10-46 \%$ [18-19]. The increased stillbirth rate in SLE is 4 fold greater than the general population [18]. Intrauterine demise and adverse fetal outcome in SLE are related in great part to lupus specific thrombophilic factors, which can cause placental infarctions, decidual vasculopathy, and lower placental weight [20-22]. Placental histopathological findings in SLE patients with lupus anticoagulant or anti-cardiolipin antibodies include extensive infarctions due to decidual vasculopathy (related to fibrinoid necrosis in the wall of decidual arterioles and thrombosis), syncytial knots, and perivillous fibrinoid change [20-22]. In addition, there is a decrease in vasculo-syncytial membranes, an increase in fibrosis and an increase in hypovascular villi all which can lead to fetal growth restriction or demise [20-22]. Pregnancy itself is a hypercoagulable state with fetal demise, thrombosis and pre-eclampsia being related to Factor V Leiden mutation, prothrombin gene mutation 20210A, and deficiencies of anti-thrombin III, protein C and protein S [23]. Thus, SLE specific thrombophilic factors are additive to the background of pregnancy related hypercoagulability (multiple hits), and this increases the occurrence of adverse fetal outcomes in lupus. 


\subsection{Premature cardiovascular disease}

Lupus-specific thrombophilic factors contribute to premature cardiac disease and atherosclerosis in this population. These lupus specific factors can affect the endothelium resulting in premature arterial vascular disease contributing to the accelerated/premature atherosclerosis observed in SLE [24]. Atheroma formation is initiated when oxidized low density lipoprotein (LDL) is taken up by foam cells in vascular endothelium [24-25]. High density lipoprotein (HDL) and Apo-A1 are protective factors against atherosclerosis. $\beta-2$ glycoprotein- 1 binding to oxidized LDL facilitates uptake by foam cells [26]. Patients with SLE have antibodies to LDL/ $\beta-2$ glycoprotein-1 complexes, HDL, and Apo -A1 [26-27]. Antibodies to HDL and Apo A-1 cross react with cardiolipin and prevent HDL and Apo-1 protection against atherosclerosis. Antibodies to oxidized LDL may cross react with $\beta$ - 2 glycoprotein- 1 and may enhance uptake, thus promoting plaque formation [25-28]. Anticardiolipin antibody binding exposes immunogenic and normally hidden (or cryptic) epitopes on $\beta-2$ glycoprotein- 1 , which can bind to anti- $\beta$ - 2 glycoprotein- 1 antibodies. These antibodies bind to adhered $\beta$ - 2 glycoprotein- 1 on endothelial cells which causes endothelial activation and subsequent up regulation of inflammatory and procoagulant factors [24-26]. In addition, adhered $\beta-2$ glycoprotein- 1 on oxidized LDL promotes LDL uptake by macrophages, thus facilitating plaque formation [24-26, 28]. During the acute phase response, HDL can be converted to pro-inflammatory molecules which promote LDL oxidation. Chronic inflammation can cause HDL dysfunction in SLE. HDL has been found to be pro-inflammatory in women with SLE and is termed pro-inflammatory HDL or piHDL $[25-26,28]$. More than $85 \%$ patients with SLE and carotid plaques had piHDL vs. $40 \%$ in those without plaques [27]. Pro- inflammatory HDL is an independent risk factor for atherosclerosis in rheumatoid arthritis and antiphospholipid antibody syndrome [26, 28]. The prevalence of moderate to severe atherosclerosis in SLE at autopsy is 52\% [29]. There is a higher prevalence of coronary artery disease in SLE than general population which is not predicted by traditional risk factors or increase in lupus activity alone [30-39]. Mortality studies show coronary artery disease (CAD) /myocardial infarction (MI) is a frequent cause of death in SLE and occurs in 11-48\% of SLE patients [3, 30-35]. Death from CAD in SLE is disproportionately larger in late disease, with CAD/MI being the leading cause of death in SLE survivors. This accounts for the late peak in mortality in SLE [36-38]. Although there are a greater number of CAD risk factors (hypertension, diabetes mellitus, dyslipidemia, sedentary life style) in SLE patients than matched controls, the increased atherosclerosis in SLE is not fully attributed to these traditional risk factors [39-41]. Several other studies have reported an increased risk of cardiovascular disease in SLE. After controlling for age, sex, cholesterol, hypertension, diabetes mellitus, tobacco use the relative risk was 10.1 for non-fatal myocardial infarction $[95 \%, \mathrm{CI}$ 5.8-15.6] and 17.0 for death due to coronary artery disease (CI 8.1-29.7) [42]. Esdaile also reported a 7.5X increased risk for developing coronary artery disease in SLE [42]. Progression of coronary artery calcification has been associated with age, cholesterol and smoking [43]. In particular, premenopausal aged women with lupus seem to have premature CAD with $>50 \mathrm{X}$ increase in MI in SLE women 35-44 years, and the risk of cardiovascular events being 8-9 X increased in middle age SLE women [44-45]. We have also reported an increased risk of myocardial infarction in premenopausal women with SLE [46]. Thus, myocardial infarctions occur in patients with SLE at younger age than the general population, and using traditional 
risk factors alone is inadequate for developing prevention and treatment programs in asymptomatic SLE patients $[42,44]$.

\subsection{Cerebrovascular disease}

Cerebrovascular disease is increased in SLE with an increased risk of stroke reported to be $1.67,3.2$ and $7.9 \mathrm{X}$ the general population [44, 47-48]. Age and hypertension are associated with progression of carotid intima media thickness and carotid artery plaque in SLE [43]. Male lupus patients tend to have a higher prevalence of strokes than females [49]. Antiphospholipid antibodies are established risk factors for ischemic stroke in lupus [50] and can increase cerebrovascular atherosclerotic disease [51].

\section{Pathogenesis and mechanisms of hypercoagulability}

\subsection{Chronic inflammation}

Chronic Inflammation, which occurs in SLE, contributes to the development of thrombosis and accelerated atherosclerosis [52]. Inflammation and infections are known epidemiologic risk factors for venous thrombosis [53]. Inflammation can cause an acquired thrombophilia and subsequent thrombosis [54]. Inflammation activates the procoagulant arm of the coagulation system and inhibits anticoagulation and fibrinolysis [55].There is an association of lupus disease activity (i.e., inflammation) and elevated erythrocyte sedimentation rate and/or Creactive protein levels with vascular thrombosis. [5, 6, 56-57]. In fact, complement activation which occurs in lupus can promote thrombosis by activating the coagulation cascade at multiple levels [58]. It is well established that venous thrombosis can occur with elevated levels of procoagulant factors 2, 8, 9 and 10, as well as with decreased levels of anticoagulant factors (antithrombin 3, protein S and protein S [54]. Coagulation factors that increase with inflammation include Von Willebrand factor, fibrinogen, Factor VII, and Factor VIII. Increases in high sensitivity C -reactive protein (HSCRP), fibrinogen and factor VIII are in seen in lupus anticoagulant-related thrombosis [59]. Additionally, fibrinogen increases with time in SLE patients which may partially explain the increased risk of thrombosis with increasing years of lupus disease $[11,60]$. Lupus disease activity is associated with elevated procoagulant markers thrombin-anti thrombin complexes, prothrombin fragment $1+2$, and soluble thrombomodulin, suggesting inflammatory mediated hypercoagulability [61]. Inflammatory cytokines promote endothelial damage, plaque formation and vascular smooth muscle hypertrophy [62]. Proinflammatory cytokines which activate endothelial and vascular smooth muscle cells include interleukin 1 (IL-1), interleukin 6 (IL-6), tumor necrosis factor (TNF) and vascular endothelial growth factor (VEGF), all of which are increased in active lupus, particularly lupus nephritis [62]. CD 40 ligand is increased in lymphocytes in SLE patients and CD40/CD40 ligand interactions can cause plaque rupture [62]. Other pro-inflammatory effects which promote atherosclerosis include chemokines and adhesion molecules. Inflammation induces thrombosis via endothelial cell dysfunction, tissue factor mediated activation of coagulation, platelet 
activation, impaired function of anticoagulants and suppressed fibrinolytic activity [55]. These effects all play a role in venous thrombosis in lupus.

\subsection{Hypercoagulability}

Multiple mechanisms contribute to hypercoagulability in SLE and thrombosis is due to multiple hits to the clotting system (the multiple-hit theory). It has been shown that elevations of procoagulant factors in combination have an additive effect on thrombosis [63]. In lupus, this includes lupus-specific and non- specific thrombogenic factors. As discussed in the previous paragraph, inflammation can cause elevations of non- lupus related procoagulant factors. Other factors contributing to hypercoagulability in SLE includes hyperhomocysteinemia [16, 64-66], and elevated plasminogen activator inhibitor-1 ( PAI-1) which decreases fibrinolytic activity [16, 55], as well as deficiencies of anticoagulant factors such as protein C, protein $\mathrm{S}$ and tissue plasminogen activator (tPA)which activates the fibrinolytic system [17, 55]. Lupus-specific procoagulant factors include antiphospholipid antibodies. Other lupusspecific factors include antibodies to factor XII [67], prothrombin [68], and annexin V [69-71]. Antiphospholipid antibodies encompass anticardiolipin antibodies, lupus anticoagulant (LAC), anti- $\beta$-2 glycoprotein-1 antibodies and false positive rapid plasma reagin (RPR) tests. These antibodies are prevalent in SLE and are pathogenically involved in the thromboses, accelerated atherosclerosis and fetal demise seen in this population. The prevalence of antiphospholipid antibodies are common in SLE with anticardiolipin antibodies occurring in $17-86 \%$ (vs.1-6\% in the general population), and LAC noted in $15-30 \%$ (vs. $1-4 \%$ in the general population) [72]. Antiphospholipid antibodies cause vascular thrombosis and fetal loss in SLE $[6,72-76]$. The LAC has a much stronger association with venous thrombosis than anticardiolipin antibodies where the thrombosis risk is directly related to increasing titers of these antibodies, particularly IGG anticardiolipin antibody titers of medium to high titer [5, 72, 77-78]. Low titers or transient presence of these antibodies generally do not cause thrombosis $[72,77]$. These antibodies bind to phospholipids and protein epitopes found in cardiolipin, annexin $\mathrm{V}$, prothrombin and $\beta-2$ glycoprotein-1 [24]. The antiphospholipid antibodies that recognize epitopes on $\beta-2$ glycoprotein-1 also bind serine proteases involved in hemostasis and fibrinolysis and hence promote thrombosis [79].

The prothrombotic effect of these antibodies occur via multiple mechanisms including platelet activation, endothelial cell activation with resultant up regulation of adhesion molecules and production of thromboxane A2, and stimulation of monocytes to make tissue factor, all of which promote clotting and vasoconstriction [80-81]. Tissue factor activates the extrinsic coagulation system while tissue plasminogen activator (tPA) activates fibrinolysis. Tissue factor pathway inhibitor activity is reduced in SLE and this is associated with increased levels of tissue factor and subsequent hypercoagulability [82]. Antiphospholipid antibodies bind to components of the coagulation cascade and activate the coagulation system leading to a procoagulant state along with decreased fibrinolysis via reducing activity of tPA [79-81].

Thrombosis and fetal loss in SLE share the same pathogenic pathways, and the mechanisms by which antiphospholipid antibodies cause fetal loss and thrombosis are complex and varied. They include target antigens in the coagulation, endothelial and immune systems summarized 
by Tripodi, et al, as follows [83]: 1.) inhibiting the protein $C$ axis (targets- protein C, protein S, thrombomodulin, activated protein $\mathrm{C}$ ((APC) resistance, endothelial protein $\mathrm{C}$ receptor, 2.$)$ increasing thrombin generation (targets- prothrombin, microparticles, tissue factor pathway inhibitor, protein Z, Factor XI, Factor XII, heparin cofactor II), 3.), disruption of the protective shield (target-annexin A5), 4.), decreasing fibrinolysis (targets-tPA, Annexin A2, $\beta$-2 glycoprotein-1 cleavage), 5.), altering complement levels (targets-C3, C5a, membrane attack complex, 6.) increasing platelet adhesion (target- Von Willebrand factor) and activation (targets-low density lipoprotein receptor 8, glycoprotein 1b, platelet factor 4, thromboxane A2, 7.) activation of endothelial cells (targets-Toll like receptor 4, tissue factor, prostacyclin, nitric oxide), 8.) activation of monocytes (target-tissue factor), 9.) activation of neutrophils (targettissue factor), 10.) trophoblast activation (target-growth factor binding), 11.) angiogenesis (target- vascular endothelial growth factor, basic fibroblast growth factor), and 12.) increased atherosclerosis ( target-oxidized LDL) [83-84]. In fact, $\beta-2$ glycoprotein-1 binds to oxidized LDL to form atherogenic complexes as discussed above. These complexes have been detected in patients with autoimmune disease and promote macrophage uptake and subsequent atherosclerosis [85].

\section{Laboratory diagnosis}

Laboratory diagnosis of hypercoagulability in lupus is complex and depends on where the patient is in the disease process. In general, more than basic tests are needed to cover the full range of possibly disrupted clotting mechanisms and this includes testing for lupus specific antiphospholipid antibodies and other hemostatic markers of coagulation. The lupus-specific antibodies include lupus anticoagulant, anticardiolipin antibodies, and anti $\beta-2$ glycoprotein- 1 antibodies. These antiphospholipid antibodies are a heterogeneous group of antibodies identified by various laboratory tests all of which have some problems with standardization, specificity, interpretation and quality control [86-89]. The target antigens for these antibodies include prothrombin, negatively charged phospholipids (such as phosphatidic acid, phosphatidylinositol and phophatidyl serine), protein C, protein S, Annexin V, $\beta$-2 glycoprotein-1, thrombomodulin, factor XII, platelet adhesive receptor glycoprotein GP $1 \mathrm{~b}$ ( which binds Von Willebrand factor) and other factors mentioned above [81, 86-90]. Anticardiolipin antibodies are directed against a protein known as $\beta-2$ glycoprotein- 1 , which binds anionic phospholipids [86-87]. Lupus anticoagulants encompass a heterogeneous group of antibodies that bind negatively charged phospholipids. The assay for LAC is a functional assay which measures the activity of these antibodies [84]. Anticardiolipin antibodies bind directly to cardiolipin as well as $\beta-2$ glycoprotein- 1 bound to cardiolipin, and are generally detected by enzyme-linked immunosorbent assay or ELISA [69]. A subgroup of these anticardiolipin antibodies bind $\beta-2$ glycoprotein-1, and it is these anticardiolipin antibodies that are pathogenic for thrombosis. $\beta-2$ glycoprotein-1 is a glycoprotein found on many cells including endothelial cells, astrocytes, neurons, extravillous cytotrophoblasts, and syncytiotrophoblast cells of the placenta [84]. $\beta-2$ glycoprotein-1 has five domains of which domain $\mathrm{V}$ binds anionic phospholipids. Antibodies to domain I seem to be the most important domain related to thrombosis [84, 87]. The anti $\beta-2$ 
glycoprotein-1 antibodies are considered a "cofactor" for anticardiolipin antibody activity but are essentially a more specific assay for evaluation of clinically relevant prothrombotic antiphospholipid antibodies [87].

Detection of these antiphospholipid antibodies by current testing is problematic due to variable performance in different laboratories as well as difficulty of standardization [83, 86-87]. The recommended method for detecting lupus anticoagulant is a functional assay and involves a 3 step process: 1) Screening via dilute Russel viper venom time or dRVVT and activated partial thromboplastin time or APTT, and if results are above normal (i.e., prolonged dRVVT or APTT) proceed to 2.) Mixing 1:1 of patient: pooled normal plasma and repeat testing. If results show that the clotting time (dRVVT and APPT) is still prolonged (i.e., not corrected), then proceed to 3.) Confirmatory step, which is to repeat testing with excess phospholipids. LAC is present if the confirmatory step shows correction of the clotting time since the LAC will bind the excess phospholipids and not the coagulation factors [83]. Anticardiolipin antibodies and anti $\beta$-2 glycoprotein-1 antibodies are both measured by ELISA. For anticardiolipin antibodies, there are specific protocols and guidelines for performing this test with some disagreement about positivity for cut off values at the lower titers [86-87, 91]. The anti $\beta-2$ glycoprotein- 1 antibody tests are also done by ELISA but are more specific than the anticardiolipin antibody ELISA test, due to having a well-defined antigen ( $\beta$-2 glycoprotein- 1 ) for this assay, and is more consistent between different laboratories. [86-87]. It is currently recommended that all three assays be done for evaluation antiphospholipid antibodies in SLE and patients classified by number and type of tests positive, with the highest risk for thrombosis being in those with positive for all three tests and particularly with the immunoglobulin $\mathrm{G}$ or IgG isotype [83]. Much work still needs to be done to improve standardization, validity and consistency of test positivity between laboratories.

Along with the antiphospholipid antibodies discussed above which must be measured in patients with thrombosis or fetal loss in lupus patients with thrombosis or fetal loss, other hemostatic markers should be measured to better assess coagulation risk in SLE, i.e., a coagulation risk laboratory profile. This includes a broad panel of testing to include fibrinogen, factor VII, factor VIII, tPA, PAI-1, plasminogen activity, Von Willebrand factor activity and antigen, protein $\mathrm{S}$ activity, protein $\mathrm{C}$ activity homocysteine, and high sensitivity $\mathrm{C}$-reactive protein or HSCRP [16]. It is also important to remember that estrogens and pregnancy can induce protein $S$ deficiency and this may compound pregnancy and hormonal therapy management in lupus. Homocysteine has been associated with thrombosis in SLE, and should be measured in lupus patients as part of any hypercoagulable work up [16, 92-94]. Interestingly, rheological evaluation of SLE patients with and without thrombosis showed no association of blood viscosity and erythrocyte aggregation with thrombosis [95].

Congenital coagulation factors have been studied in in a limited fashion in SLE. The MTHFR $677 \mathrm{C}>\mathrm{T}$ polymorphism is associated with elevated homocysteine. This polymorphism was found to be homozygous form in $16.7 \%$ and heterozygous form in $83.3 \%$ of SLE patients tested and the homozygous form was increased in SLE patients vs. controls [57]. On the other hand, Factor V Leiden and Prothrombin G20210AS gene polymorphisms were not increased in SLE patients with thrombosis $[64,94]$. These 2 gene polymorphisms are generally seen in Northern 
European Caucasian populations so it is not surprising that SLE populations, being more predominantly African American, would not show any increase of these gene types. The PROFILE cohort study by Kaiser, et al, assessed 33 single nucleotide polymorphisms (SNPs) in 1,361 predominantly Caucasian SLE patients and found that genetic risk factors for thrombosis in this cohort differed across ethnic groups, and there was an association of venous thrombosis and SNPs for these genes in whites for Factor V Leiden ( $\mathrm{OR}=2.69, \mathrm{p}=0.002)$, for MTHFR (OR=1.51, $\mathrm{p}=0.01)$, and for fibrinogen gamma $(\mathrm{OR}=1.49, \mathrm{p}=0.02)$ [96]. Evaluation of functional polymorphisms of the coagulation Factor II gene, which is associated with elevated levels and activity of prothrombin and thrombosis, showed an association of one particular polymorphism (rs313516 G allele) with SLE susceptibility in African Americans and Caucasians [97]. Micro-RNAs are non-coding RNAs which function to control gene regulation post transcription by regulating mRNA translation or stability. One study assessing micro-RNAs in SLE showed that specific micro-RNAs resulted in increased tissue factor production and increased procoagulant activity [98]. There is limited data on PAI-1 promoter 4G/5G polymorphisms in SLE. Increased PAI-1 activity is associated with reduced endogenous fibrinolytic activity and is a risk factor for thrombosis. The $4 \mathrm{G} / 4 \mathrm{G}$ genotype for PAI-1 promoter has the highest levels of PAI-1 activity and hence the highest risk for thrombosis. SLE patients with the 4G/4G genotype were found to have increased carotid atherosclerosis [99]. In addition, SLE patients with PAI-1 4G/4G homozygosity were at increased risk for glomerular microthrombi [100]. An additional risk factor for the development of arterial thrombosis in antiphospholipid antibody syndrome is the presence of the $4 \mathrm{G}$ allele of the $4 \mathrm{G} / 5 \mathrm{G}$ polymorphism of the PAI- 1 gene [101].

\section{Platelet function in SLE}

Although platelet hyperfunction plays an important role in thrombosis in SLE, it has not been well studied in this population. There is some evidence that platelet activation occurs in SLE and is associated with thrombosis [102-105]. Platelet hyperfunction and platelet activation can be induced by inflammation or antiphospholipid antibodies [106-108]. Antiphospholipid antibodies have been shown to bind to $\beta-2$ glycoprotein-1 -phospholipid complexes on activated platelet membranes. Sticky platelet syndrome or hyperfunctioning platelets is a well described autosomal dominant disorder associated with arterial and venous thrombosis and characterized by hyperaggregable platelets in response to adenosine diphosphate (ADP), epinephrine or both [109-111]. Hyperaggregable platelets have been described in other conditions including diabetes, unstable angina, atrial fibrillation, thrombotic strokes, migraine headaches, retinal artery occlusions, pre-eclampsia, arterial thromboembolism, nephrotic syndrome and patients in intensive care units [109-111]. This suggests that platelet aggregation is a response to stress or epinephrine [109-111]. In women with recurrent miscarriages, sticky platelet syndrome was found in $21 \%$ [112]. Enhanced platelet aggregation was noted in nonlupus patients with venous thromboembolism [113]. It is logical to assume that SLE patients would have activated platelets and platelet hyperfunction due to stress, inflammation and antiphospholipid antibody mediated activation. Few studies have assessed platelet function 
in SLE. Platelet activation markers CD 62 and CD 63 are increased in patients with primary antiphospholipid antibody syndrome, suggesting platelet activation plays an important role in thrombosis mediated by antiphospholipid antibodies [114]. In vitro platelet activation measured by flow cytometry using anti CD 62 was augmented by the presence of lupus plasma samples containing anticardiolipin antibodies and LAC [115]. Persistent activation of platelets (measured by platelet induced extracellular phosphorylation of plasma proteins) was seen in lupus patients, particularly those with thrombosis but not in non-SLE patients with DVT [116]. Our study (Dhar, et al) showed that 70\% of SLE patients who had a hypercoaguable state had hyperfunctioning platelets measured by a functional assay [16].

Platelet hypofunction can also occur in SLE and has also not been well studied. Platelet hypofunction is usually the result of platelet dense granule deficiency and can result in bleeding and bruising disorders. Prolonged bleeding times suggesting platelet hypofunction have been described lupus patients who had LAC [117]. Our study (Dhar, et al) showed that the patients who had bleeding problems had platelet dense granule deficiency as measured by electron microscopy [16].

\section{Approach to patients: Work up and thrombophilia management}

\subsection{High risk clinical scenarios}

Selecting SLE patients for a coagulation assessment is well established for those with a thrombosis or fetal loss but is not well defined for those who are at risk but have not yet had an event. Thus, patients who have had an event should clearly be selected for a coagulation work up. The guidelines for this are the Sydney Clinical Criteria for antiphospholipid antibody syndrome [118]. This includes any 1.) vascular ( arterial, venous or small vessel) thrombosis except for superficial thrombosis, 2.) Pregnancy morbidity (one or more unexplained deaths of a morphologically normal fetus at or beyond 10 weeks of gestation, one or more premature births of a morphologically normal neonate at or before 34 weeks gestation due to severe preeclampsia, eclampsia or severe placental insufficiency, or three or more unexplained consecutive spontaneous abortions before the $10^{\text {th }}$ week of gestation excluding anatomic or hormonal abnormalities or maternal/paternal chromosomal causes [118]. However, medical management should advance towards prevention of thrombosis and adverse fetal outcomes and one should evaluate high risk clinical settings as reason enough for a thrombophilic risk assessment. These would include pregnancy, pre-estrogen hormone therapy, pre-tamoxifen therapy, pre-organ transplant, pre- vascular procedure (such as coronary artery stenting), pulmonary hypertension, nephrotic syndrome, and chronic inflammatory setting, etc. In other words, one should assess the risk of thrombosis in the clinical situation and assess the multiple hits on that background. If the clinical setting is high risk for thrombophilia, one should do the coagulation profile discussed above along with genetics and platelet function studies. Then once this information is obtained, one should assess the number and degree of procoagulant hits and determines a treatment plan. This allows fine tuning of treatment while minimizing bleeding risk. Treatment strategies should be tailored to minimize bleeding complications, reduce 
recurrence of thrombosis, reduce intrauterine fetal demise, and simplify monitoring. Another complicating issue for thrombophilia management is that SLE patients frequently have mixed disorders with both prothrombotic and bleeding tendencies. Thus, when ordering a laboratory work up, an extensive battery of tests is needed to most accurately define the coagulation status. Unfortunately, since these factor abnormalities are independent of each other for the most part, there is no way to truncate the testing to an algorithm. However, as much information as possible should be obtained to determine the procoagulant and anticoagulant factors that would increase the risk for thrombosis and decide on optimal treatment.

\subsection{Thromboprophylaxis for hypercoagulable states}

For those SLE patients with hypercoagulability who have not had a thrombosis, treatment options for hypercoagulability in lupus consist of thromboprophylaxis for acute high risk situations, chronic prophylaxis for thrombosis prevention, and full dose anticoagulation therapy. Thromboprophylaxis for patients without any history of thrombosis and presence of antiphospholipid antibodies is controversial. However, evaluating thrombosis risk by assessing the multiple hits with a full thrombophilia profile would provide more support for deciding on intensity and type of thromboprophylactic treatment. High risk settings for which acute/short term thromboprophylaxis is indicated for antiphospholipid antibody positive patients would include surgery, ovarian stimulation or other short term hormonal therapy, pregnancy, vascular procedures, lupus flares, infections, and prolonged immobilization [119]. In pregnant SLE patients positive for lupus anticoagulant, it is recommended that low dose molecular weight or unfractionated heparin be used during pregnancy since neiher cross the placenta [19]. It is not recommended to treat thrombophilia in pregnant SLE patients who are positive for anti cardiolipin antibodies or lupus anticoagulant with corticosteroids since only anticoagulation has been shown to be of proven benefit in preventing thrombosis and fetal loss [19]. Corticosteroids have no benefit in preventing thrombotic complications in this setting and should only be used if any active lupus disease is present [19]. In addition, there is no role for prophylactic corticosteroids in patients who have no active lupus disease. Corticosteroids are relatively safe to use during pregnancy from a fetal standpoint, since the placenta metabolizes $90 \%$ of non-flourinated corticosteroids. However, corticosteroids increase maternal complications such as hypertension and gestational diabetes [19]. Appropriate settings for chronic thromboprophylaxis would include those patients with persistent medium to high titers of anticardiolipin antibodies, those with triple antiphospholipid antibody positivity (+LAC, +anticardiolipin antibody, and +anti $\beta$-2 glycoprotein-1 antibody), and those with multiple hits on a background of high risk clinical settings such as, long term hormonal therapy, nephrotic syndrome, cardiovascular disease, and history of obstetric antiphospholipid antibody related events [119]. Both platelet function and the balance of procoagulant and anticoagulant factors should be assessed. Low dose aspirin therapy for prophylaxis is recommended by the Task Force at the $13^{\text {th }}$ International congress on Antiphospholipid Antibodies for these aforementioned situations along with lifestyle changes and is commonly accepted as standard treatment by many [120-121]. In SLE patients with antiphospholipid antibodies, the task force recommends both low dose aspirin and hydroxychloroquine [120]. In pregnant SLE patients with antiphospholipid antibodies only and no previous history of pregnancy loss, low 
dose aspirin is recommended [122]. If platelet hyperfunction is present, low dose aspirin is indicated. If hyperhomocysteinemia is present, folic acid and B complex should be used to lower homocysteine levels to below $10 \mu$ moles/liter. However, if other high risk situations are identified in which thrombosis is likely, such as very low protein S activity, then anticoagulation with warfarin or low molecular weight heparin is indicated.

\subsection{Treatment of hypercoagulable states with prior vascular thrombosis}

For those SLE patients with antiphospholipid antibodies and hypercoagulablity who have had an arterial or venous thrombosis full dose anticoagulation is recommended with unfractionated or low molecular weight heparin (e.g., enoxaparin, dalteparin), fondaparinux (a synthetic of the minimal anti thrombin binding sequence of heparin), vitamin $\mathrm{K}$ antagonists (e.g., warfarin), direct thrombin inhibitors (e.g., dabigatran), or direct factor Xa inhibitors (e.g., rivaroxaban) $[83,123]$. For acute arterial or venous thrombosis, treatment consists of an initial course of unfractionated or low molecular weight heparin followed by indefinite long term treatment with warfarin to keep the international normalized ration or INR between 2.0-3.0, heparin- type drugs, or more recently, one of the newer thrombin or factor Xa inhibitors. For arterial thrombosis (stroke, myocardial infarction), addition of antiplatelet agents (low dose aspirin, clopidogrel $75 \mathrm{mg}$ ) may be helpful, particularly if platelet hyperfunction is present [16, 83]. The disadvantage of using warfarin is the difficulty of maintaining the correct therapeutic INR range and frequency of INR testing that must be done, which is inconvenient to the patient. The disadvantage of the heparin- type drugs is that the patient must administer self-injections daily. The heparin- type drugs do have one advantage in that coagulation lab monitoring is unnecessary. The newer thrombin or factor Xa inhibitor drugs have the dual advantage of being an oral medication and not requiring laboratory anticoagulation monitoring. For catastrophic antiphospholipid antibody syndrome, which has a high mortality rate, treatment with plasma exchange, high dose corticosteroids, intavenous immunoglobulins and anticoagulation is recommended [124].

\subsection{Pregnancy}

SLE pregnancies should be considered high risk and must be managed in a multidisciplinary setting to address three problem areas: hypertensive pregnancy complications, lupus disease activity and thrombophilia [19]. Pregnancy is a hypercoagulable state which is worsened by the inflammation of active lupus disease. Pregnancy outcomes are worse with active lupus, particularly nephritis and active central nervous system (CNS) disease. Thus, it is recommended that patients with SLE have planned pregnancies and not attempt conception until the disease has been in remission for the preceeding 6 months [19]. Pregnancies that occur during active lupus or in patients with a history of severe major organ involvement such as nephritis or CNS disease are higher risk for poor fetal outcomes and maternal complication [19].Patients with mild disease generally have good pregnancy outcomes. For those pregnant SLE patients with no prior pregnancy loss or previous vascular thrombosis who have anti phospholipid antibodies, it is recommended that prophylaxis with low dose aspirin be used [125]. However if there are multiple hits such as triple antiphospholipid antibody positivity, 
low dose aspirin along with prophylactic doses of unfractionated or low molecular weight heparin be used [125-126]. Pregnancy-induced protein S deficiency can occur in these patients and when present should be treated with full dose anticoagulation with of unfractionated or low molecular weight heparin to prevent pregnancy loss. For pregnant SLE patients with antiphospholipid antibodies, other hypercoagulability factors, and a previous pregnancy loss or vascular thrombosis, treatment with full dose of unfractionated or low molecular weight heparin along with dose aspirin is recommended [127-128]. Generally anticoagulation is interrupted briefly during the delivery period and resumed and continued post- partum until the protein $S$ levels return to normal and the other coagulation parameters correct. For antiphospholipid antibody persistence post-partum, continued treatment with daily aspirin is often used. Although these treatments for pregnant SLE patients are generally accepted, there is a lack of definitive data from clinical trials to support these accepted regimens [83].

\subsection{Adjuvant treatments}

Other adjuvant treatments summarized by Mehudi [81] for antiphosphoipid antibodies in SLE include: 1.) statins (which decrease antiphospholipid antibody mediated thrombosis and inflammation, 2.)Ritxuamib (which depletes CD 20 B lymphocyte cells involved in antiphospholipid antibodyl mediated disease), 3.) Hydroxychloroquine (which inhibit platelet aggregation of antiphospholipid- activated platelets by binding to GPIIbIIIa and by binding $\beta-2$ glycoprotein-1 or to target cells), 4.) Specific GPIIbIIIa inhibitors (e.g,abciximb) which bind and inactivate GPiia IIIb which is upregulated on antiphospholipid antibody activated platelets, 5.) inhibitors of tissue factor up regulation seen in antiphopholipid antibody activated endothelial cells (e.g., ACE inhibitors), 6.) anti TNF therapy to block high TNF levels seen in antiphospholipid antibody positive patients, 7.) blockage of receptors for $\beta-2$ glycoprotein-1 or antiphospholipid antibodies on target cells [81].

\section{Conclusion}

It is clear that thrombophilia assessment and management is complex in SLE. The balance of procoagulant factors, anticoagulant factors and platelet function determine the overall hypercoagulability risk. Simply testing for antiphospholipid antibodies alone is inadequate for determining thrombophilia status and risk in SLE. Extended coagulation profile testing along with genetic evaluation of procoagulant markers and measurements of platelet function provide more clear and precise information to develop a thrombotic or fetal loss risk assessment in SLE. This allows for fine tuning of prophylactic or full dose anticoagulation treatment and may help determine intensity and length of treatment. The overall benefit of this extended testing is to improve selection of patients to treat, improve management of anticoagulation therapy, reduce re-thrombosis and fetal loss risk, and minimize treatment complications. Further research is needed to better elucidate the multiple mechanisms behind hypercoagulability in lupus with thrombotic risk stratification and subsequent development of more definitive treatment recommendations. 


\section{Author details}

Patricia J. Dhar and Robert J. Sokol

Wayne State University School of Medicine, Departments of Internal Medicine and Obstetrics \& Gynecology, Division of Rheumatology, C.S. Mott Center for Human Growth and Development, Detroit, Michigan, USA

\section{References}

[1] Villa-Blanco I, Calvo-Alen J. Utiliizing Registries in Systemic Lupus Erythematosus Clinical Research. Expert Rev 2012; 8(4): 353-360

[2] Feldman, CH, Hiraki LT, Liu J, Fischer MA, Solomon DH, Alarcon GS, Winkelmayer WC, Costenbader KH. Arthritis and Rheumatism 2013; 65(3); 753-763.

[3] Cervera R, Khamashta MA, Font J, Sepastiani GD, Gil A, Lavilla P, Meja JC, Aydintug AO, Chwalinska-Sadowska H, de Ramon E, Fernandez-Nebro A, Galeazzi M, Valen M, Mathieu A, Houssiau F, Caro N, Alba P, Ramon-Casals M, Ingelmo M, Hughes GR; European Working Party on Systemic Lupus Erythematosus. Morbidity and mortality in systemic lupus erythematosus during a 10-year period: a comparison of early and late manifestations in a cohort of 1,000 patients. Medicine (Baltimore) 2003; 82: 299-308.

[4] Sarabi ZS, Chang E, Bobba R, Ibanez D, Gladman D, Urowitz M, Forin PR. Incidence rates of aterial and venous thrombosis after diagnosis of systemic lupus erythematosus. Arthritis and Rheumatism 2005; 53: 609-12.

[5] Calvo-Alen J, Toloza SMA, Fernandez M, Bastian HM, Fessler BJ, Roseman JM, McGwin G, Vila LM, Reveille JD, Alarcon GS for the LUMINA Study Group. Systemic lupus erythematosus in a multiethnic US cohort (LUMINA): XXV, Smoking, older age, disease activity, lupus anticoagulant, and glucocorticoid dose as risk factors for the occurrence of venous thrombosis in lupus patients. Arthritis and Rheumatism 2005; 52: 2060-8.

[6] Toloza SMA, Uribe AG, McGwin G, Alacron GS, Fessler BJ, Bastian HM, Vila LM, Wu R, Shoenfeld Y, Roseman JM, Reveille JD for the LUMINA Study Group. Systemic lupus erythematosus in a multiethnic US cohort (LUMINA); XXIII, Baseline predictors of vascular events. Arthritis and Rheumatism 2004; 50: 3947-57.

[7] Calvo-Alen J, Alarcon GS, Tew MB, Tan FK, McGwin G, Fessler BJ, Vila LM, Reveille JD for the LUMINA Study Group. Systemic lupus erythematosus in a multiethnic US cohort. XXXIV, Deficient mannose-binding lectin exon 1 polymophisms are associated with cerebrovascular but not with other arterial thrombotic events. Arthritis and Rheumatism 2006; 54: 1940-5. 
[8] Cervera R, Khamashta MA, Font J, Sebastiani GD, Gil A, Lavilla P, Aydintug AO, Jedryka-Góral A, de Ramón E, Fernández-Nebro A, Galeazzi M, Haga HJ, Mathieu A, Houssiau F, Ruiz-Irastorza G, Ingelmo M, Hughes GR. Morbidity and mortality in systemic lupus erythematosus during a 5-year period. A multicenter prospective study of 1,000 patients. European Working Party on Systemic Lupus Erythematosus. Medicine (Baltimore). 1999 May;78(3):167-75

[9] Stefanidou, S, Benos,A, Galanopoulou,V, Chatziyannis,I, Kanakoudi,F, Aslanidis, S, Boura,P, Sfetsios,T, Settas,T, Katsounaros,M, Papadopoulou, D, Giamalis, P,Dombros, Chatzistilianou, N, Garyfallos, AClinical expression and morbidity of systemic lupus erythematosus during a post-diagnostic 5-year follow-up: a male:female comparison. Lupus (2011) 20, 1090-1094.

[10] Chang ER., Pineau CA, Bertansky S, Neville C, Clarke AE, Portin PR. Risk for incident arterial or venous vascular events varies over the course of systemic lupus erythematosus. J Rheumatol. 2006; 33(9):1780-4

[11] Somers E, Mager LS, Petri M. Antiphospholipid antibodies and incidence of thrombosis in a cohort of patients with systemic lupus erythematosus. J Rheumatol 2002; 29: 2531-6.

[12] Fernandez M, Calvo-Alen J, Alarcon GS, Roseman JM, Bastian HM, Fesler BJ, McGwin G, Vila LM, Sanchez ML. Reveille JD for the LUMINA study group. Systemic lupus erythematosus in a multiethnic US cohort (LUMINA). XXI. Disease activity, damage accrual, and vascular events in pre- and postmenopausal women. Arthritis and Rheumatism 2005;52: 1655-64.

[13] Burgos PI, Alarcón GS. Thrombosis in systemic lupus erythematosus:risk and protection. Expert Rev Cardiovasc Ther 2009; 7:1541-9.

[14] Sallai KK, Nagy E, Bodo I, Mohl A, Gergely P. Thrombosis risk in systemic lupus erythematosus: the role of thrombophilic riskfactors. Scand J Rheumatol 2007; 36: 198-205.

[15] Martínez-Berriotxoa A, Ruiz-Irastorza G, Egurbide MV, Rueda M, Aguirre C. Homocysteine, antiphospholipid antibodies and risk of thrombosis in patients with systemic lupus erythematosus. Lupus 2004; 13: 927-33.

[16] Dhar JP, Andersen J, Essenmacher L, Ager J, Sokol RJ. Thrombophilic Patterns of Coagulation Factors in Systemic Lupus Erythematosus. Lupus 2009;18; 400.

[17] Yasmeen S, Wilkins EE, Field NT, Sheikh RA, Gilbert WM. Pregnancy outcomes in women with systemic lupus erythematosus. J Matern Fetal Med. 2001 Apr;10(2):91-6

[18] Dhar JP, Essenmacher L, Ager J, Sokol RJ. Pregnancy Outcomes Before and After Diagnosis of Systemic Lupus Erythematosus: American Journal of Obstetrics \& Gynecology: 193; 1444-55, 2005. 
[19] Dhar, JP, Sokol RJ. Lupus and Pregnancy: Complex Yet Manageable. Clinical Medicine \& Research 2006; 4(4): 310-320.

[20] Ogishima D, Matsumoto T, Nakamura Y, Yoshida K, Kuwabara Y. Placental pathology in systemic lupus erythematosus with antiphospholipid antibodies. Pathol Int. 2000 Mar;50(3):224-9.

[21] Out HJ, Kooijman CD, Bruinse HW, Derkson RHWM. Histopathological Findings in Placentae from Patients with Intra-uterine Fetal Death and Anti-phospholipid Antibodies. European Journal of Obstetrics \& Gynecology and Reproductive Biology 1991; 41: 179-186.

[22] Arias F, Romero R, Joist H, Kraus FT. Thrombophilia: a Mechanism of Disease in Women with Adverse Pregnancy Outcome and Thrombotic Lesions in the Placenta. J Matern Fetal Med 1998; 7(6): 277-286.

[23] Arkel YS, Ku DH.Thrombophilia and pregnancy: review of the literature and some original data.Clin Appl Thromb Hemost. 2001 Oct;7(4):259-68.

[24] Feinbloom D, Bauer K. Assessment of hemostatic risk factors in predicting arterial thrombotic events. Arteriosclerosis, Thrombosis, and Vascular Biology 2005; 25: 2043-53.

[25] Goyal T, Mitra S, Khaidakov M, Wang X, Singla S, Ding Z, Liu S, Mehta JL. Current Concepts of the Role of Oxidized LDL Receptors in Atherosclerosis. Curr Atheroscler Rep. 2012 Jan 29. (Epub ahead of print)

[26] Hahn BH, McMahon M. Atherosclerosis and systemic lupus erythematosus: the role of altered lipids and of autoantibodies. Lupus. 2008 May;17(5):368-70.

[27] McMahon M, Grossman J, Skaggs B, Fitzgerald J, Sahakian L, Ragavendra N, Charles-Schoeman C, Watson K, Wong WK, Volkmann E, Chen W, Gorn A, Karpouzas G, Weisman M, Wallace DJ, Hahn BH. Dysfunctional proinflammatory high-density lipoproteins confer increased risk of atherosclerosis in women with systemic lupus erythematosus. Arthritis Rheum. 2009 Aug;60(8):2428-37.

[28] Hahn BH, Grossman J, Chen W, McMahon M.The pathogenesis of atherosclerosis in autoimmune rheumatic diseases: roles of inflammation and dyslipidemia.J Autoimmun. 2007 Mar-May;28(2-3):69-75. Epub 2007 Apr 16.

[29] Abu-Shakra M, Urowitz MB, Gladman DD, Gough J.Mortality studies in systemic lupus erythematosus. Results from a single center. I. Causes of death.J Rheumatol. 1995 Jul;22(7):1259-64.

[30] Urowitz MB, Gladman DD, Tom BD, Ibañez D, Farewell VT. Changing patterns in mortality and disease outcomes for patients with systemic lupus erythematosus. J Rheumatol. 2008 Nov;35(11):2152-8. Epub 2008 Sep 15.

[31] Gustafsson J, Simard JF, Gunnarsson I, Elvin K, Lundberg IE, Hansson LO, Larsson A, Svenungsson E. Risk factors for cardiovascular mortality in patients with systemic 
lupus erythematosus, a prospective cohort study.Arthritis Res Ther. 2012 Mar 5;14(2):R46. (Epub ahead of print)

[32] Doria A, Iaccarino L, Ghirardello A, Zampieri S, Arienti S, Sarzi-Puttini P, Atzeni F, Piccoli A, Todesco S. Long-term prognosis and causes of death in systemic lupus erythematosus. Am J Med. 2006 Aug;119(8):700-6.

[33] Chambers SA, Allen E, Rahman A, Isenberg D. Damage and mortality in a group of British patients with systemic lupus erythematosus followed up for over 10 years. Rheumatology (Oxford). 2009 Jun;48(6):673-5. Epub 2009 Apr 9.

[34] Björnådal L, Yin L, Granath F, Klareskog L, Ekbom A.Cardiovascular disease a hazard despite improved prognosis in patients with systemic lupus erythematosus: results from a Swedish population based study 1964-95. J Rheumatol. 2004 Apr;31(4): 713-9.

[35] Souza DC, Santo AH, Sato EI. Mortality profile related to systemic lupus erythematosus: a multiple cause-of-death analysis.J Rheumatol. 2012 Mar;39(3):496-503. Epub 2012 Jan 15.

[36] Rubin, LA, Urowitz MB, Gladmann DD. Mortality in systemic lupus erythematosus:the bimodal pattern revisited. Q J Med 1985: 55: 87-98

[37] Urowitz MB, Bookman AAM, Koehler BE, Gordan DA, Smythe HA, Ogryzlo MA: the bimodal mortality pattern of systemic lupus erythematosus. Am J Med 1976; 60: 221-5

[38] Symmons DP, Gabriel SE.Epidemiology of CVD in rheumatic disease, with a focus on RA and SLE. Nat Rev Rheumatol. 2011 May 31;7(7):399-408. doi: 10.1038/nrrheum. 2011.75.

[39] Asanuma Y, Oeser A, Shintani AK, Turner E, Olsen N, Fazio S, Linton MF, Raggi P, Stein CM. Premature coronary-artery atherosclerosis in systemic lupus erythematosus. N Engl J Med. 2003 Dec 18;349(25):2407-15.

[40] Roman MJ, Crow MK, Lockshin MD, Devereux RB, Paget SA, Sammaritano L, Levine DM, Davis A, Salmon JE. Rate and determinants of progression of atherosclerosis in systemic lupus erythematosus. Arthritis Rheum. 2007 Oct;56(10):3412-9.

[41] Roman MJ, Shanker BA, Davis A, Lockshin MD, Sammaritano L, Simantov R, Crow MK, Schwartz JE, Paget SA, Devereux RB, Salmon JE. Prevalence and correlates of accelerated atherosclerosis in systemic lupus erythematosus. N Engl J Med. 2003 Dec 18;349(25):2399-406. Erratum in: N Engl J Med. 2006 Oct 19;355(16):1746.

[42] Esdaile JM, Abrahamowicz M, Grodzicky T, Li Y, Panaritis C, du Berger R, Côte R, Grover SA, Fortin PR, Clarke AE, Senécal JL. Traditional Framingham risk factors fail to fully account for accelerated atherosclerosis in systemic lupus erythematosus. Arthritis Rheum. 2001 Oct;44(10):2331-7. 
[43] Kiani AN, Post WS, Magder LS, Petri M. Predictors of progression in atherosclerosis over 2 years in systemic lupus erythematosus. Rheumatology (Oxford). 2011 Nov; 50(11):2071-9. Epub 2011 Aug 28.

[44] Manzi S, Meilahn EN, Rairie JE, Conte CG, Medsger TA Jr, Jansen-McWilliams L, D'Agostino RB, Kuller LH. Age-specific incidence rates of myocardial infarction and angina in women with systemic lupus erythematosus: comparison with the Framingham Study. Am J Epidemiol. 1997 Mar 1;145(5):408-15.

[45] Bengtsson C, Bengtsson A, Costenbader Kh, Jönsen A, Rantapää-Dahlqvist S, Sturfelt G, Nived O.Systemic lupus erythematosus and cardiac risk factors: medical record documentation and patient adherence.Lupus. 2011 Oct;20(10):1057-62. Epub 2011 Jun 15.

[46] Dhar JP, Essenmacher L, Ager J, Chiodo L, Schultz D, Stark A, Schwartz A, Gregoire L, Sokol RJ. Premature cardiovascular aging in women with systemic lupus erythematosus. Presented at the $59^{\text {th }}$ Annual Scientific Meeting of the Society of Gynecological Investigation, San Diego, California, March 2012 and Reproductive Sciences 19 (3 supplement):T-196, 2012.

[47] Chiu CC, Huang CC, Chan WL, Chung CM, Huang PH, Lin SJ, Chen JW, and Leu HB. Increased Risk of Ischemic Stroke in Patients with Systemic Lupus Erythematosus:A Nationwide Population-based Study. Intern Med 51: 17-21, 2012 DOI: 0.2169/ internalmedicine.51.6154

[48] Wang IK, Muo CH, Chang YC, Liang CC, Lin SY, Chang CT, Yen TH, Chuang FR, Chen PC, Huang CC, Sung FC. Risks, subtypes, and hospitalization costs of stroke among patients with systemic lupus erythematosus: a retrospective cohort study in Taiwan. J Rheumatol. 2012 Aug;39(8):1611-8. Epub 2012 Jul 1.

[49] Stefanidou S, Benos A, Galanopoulou V, Chatziyannis I, Kanakoudi F, Aslanidis S, Boura P, Sfetsios T, Settas L, Katsounaros M, Papadopoulou D, Giamalis P, Dombros N, Chatzistilianou M, and Garyfallos A. Clinical expression and morbidity of systemic lupus erythematosus during a post-diagnostic 5-year follow-up: a male:female comparison. Lupus (2011) 20, 1090-1094.

[50] Brey RL, Muscal E, and Chapman J. Antiphospholipid antibodies and the brain: A consensus report. Lupus 2011 20: 153.

[51] Hortsman LL, Jy W, Bidot CJ, et al. Antiphospholipid antibodies: paradigm in transition. J Neuroinflammation 2009: 6: 3 From BREY

[52] Aksu K, Donmez A., and Kese, G..Inflammation-Induced Thrombosis: Mechanisms, Disease Associations and Management. Current Pharmaceutical Design, 2012, 18, 1478-1493

[53] Tichelaar YIGV, Kluin-Nelemans HJC, Karina-Meijer K. Infections and inflammatory diseases as risk factors for venous thrombosis. Thromb Haemost 2012; 107: 827-837 
[54] Nicolaides AN, Breddin HK, Carpenter P, Coccheri S, Conrad J, De Stefano V, Elkoofy N, Gerotziafas G, Guermazi S, Haas S, Hull R, Kalodiki E, Kristof V, Michiels JJ, Myers K, Pineo G, Prandoni P, Romeo G, Samama MM, Simonian S, Xenophontos S. Consensus Statement: Thrombophilia and Venous Thromboembolism. International Consensus Statement. Guidelines according to scientific evidence. International Angiology 2005; 24: 1-26.

[55] Margetic S, Inflammation and haemostasis. Biochemia Medica 2012;22(1):49-62

[56] Vila LM, Alarcon GS, McGwin G, Bastian HM, Fessler BJ, Reveille JD; LUMINA Study Group. Systemic lupus erythematosus in a multiethnic cohort (LUMINA): XXIX. Elevation of erythrocyte sedimentation rate is associated with disease activity and damage accrural. J Rheumatol 2005; 32: 2150-5.

[57] Pullmann Jr. R, Skerenova M, Lukac J, Hybenova J, Melus V, Kubisz P, Rovensky J, Pullman J. Factor V Leiden and Prothrombin G20210A mutations and the risk of atherothrombotic events in systemic lupus erythematosus. Clinical and Applied Thrombosis/Hemostasis 2004; 10: 233-8.

[58] Oikonomopoulou K, Ricklin D, Ward PA, John D, Lambris JD. Interactions between coagulation and complement-their role in Inflammation. Semin Immunopathol. 2012 January ; 34(1): 151-165. doi:10.1007/s00281-011-0280-x.

[59] Sailer T, Vormittag R, Pabinger I, Vukovich T, Lehr S, Quehenberger P, Panzer S, Lechner K, Zoghlami-Rintelen C. Inflammation in patients with lupus anticoagulant and implications for thrombosis. J Rheumatol. 2005 Mar;32(3):462-8.

[60] Ames PR, Alves J, Pap AF, Ramos P, Khamashta MA, Hughes GR.Fibrinogen in systemic lupus erythematosus: more than an acute phase reactant? J Rheumatol. 2000 May;27(5):1190-5.

[61] Kiraz S, Ertenli I, Benekli M, Haznedaroğlu IC, Calgüneri M, Celik I, Apraş S, Kirazli S. Clinical significance of hemostatic markers and thrombomodulin in systemic lupus erythematosus: evidence for a prothrombotic state. Lupus. 1999;8(9):737-41.

[62] Frieri M. Accelerated atherosclerosis in systemic lupus erythematosus: role of proinflammatory cytokines and therapeutic approaches. Curr Allergy Asthma Rep. 2012 Feb;12(1):25-32.

[63] Male C, Foulon D, Hoogendoom H, Vegh P, Silverman E, David M, Mitchell L. Predictive value of persistent versus transient antiphospholipid subtypes for the risk of thrombotic events in pediatric patients with systemic lupus erythematosus. Blood 2005; 106: 4152-8.

[64] Alfetra A, Vadacca M, Conti L, Galluzo S, Mitterhofer AP, Ferri GM, Del- Porto F, Caccavo D, Gandolfo GM, Amoroso A. Thrombosis in systemic lupus erythematosus: congenital and acquired risk factors. Arthritis and Rheumatism 2005; 53: 452-9.

[65] Onetti L, Villafane S, Menso E, Drenkard C, Gamron S, Barberis G, Onetti CM. Hyperhomocysteinemia as a thrombotic risk factor in patients suffering from systemic 
lupus erythematosus and antiphospholipid syndrome. Rev Fac Cien Med Univ Nac Cordoba 2005; 62: 19-23.

[66] Petri M, Roubenoff R, Dallal G, Nadeau MR, Selhub J, Rosenberg IH. Plasma homocysteine as a risk factor for atherothrombotic events in systemic lupus erythematosus. The Lancet 1996; 348: 1120-4.

[67] Bertolaccini M, Mepani K, Sanna G, Hughes GR, Khamashta, MA. Faxtor XII autoantibodies as a novel marker for thrombosis and adverse obstetric history $\mathrm{n}$ patients with systemic lupus erythematosus. Ann Rheum Dis 2007; 66:533-6

[68] Bizzaro N, Ghiradelio A, Zampieri S, Iaccarino L, Tozzoli R, Ruffatti A, Villalta D, Tonutti E, Doria A. Anti-thrombotic autoantibodies predict thrombosis in patients with systemic lupus erythematosus: a 15 year longitudinal study. J Thromb Haemost 2007 March 21 Epub ahead of print.

[69] de Laat B, Wu XX, van Lummel M, Derksen RHWM, de Groot PG, Rand JH. Correlation between antiphospholipid antibodies that recognize domain I of $\beta 2$-glycoprotein 1 and a reduction in the anticoagulant activity of annexin A5. Blood 2007; 109: 1490-4.

[70] Esposito G, Tamby MC, Chanseaud Y, Servettaz A, Guillevin L, Mouthon L. Autoimmunity reviews 2005; 4: 53-60.

[71] Cererholm A, Svenungsson E, Jensen-Urstad K, Trollmo G, Ulfgren AK, Svendenborg J, Fei GZ, Frostegard J. Decreased binding of Annexin V to entothelial cells: a potential mechanism in atherothrombosis of patients with systemic lupus erythematosus. Artheriosclerosis, Thrombosis, and Vascular Biology 2005; 25: 198-203.

[72] Petri M. Epidemiology of the antiphospholipid antibody syndrome. Journal of Autoimmunity 2000; 15: 145-51.

[73] Petri M. Thrombosis and systemic lupus erythematosus: the Hopkins Lupus Cohort perspective. Scand J Rheumatol 1996; 25: 191-3.

[74] Barcat D, Guerin V, Ryman A<Constans J, Vernhes JP, Vergnes C, Bonnet F, Delbrel $\mathrm{X}$, Marlat P, Longy-Boursier M, Conri C. Thrombophilia and thrombosis in systemic lupus erythematosus; a case control study. Ann Rheum Dis 2003; 62: 1016-7.

[75] Mok CC, Tang SSK, To CH, Petri M. Incidence and risk factors of thromboembolism in systemic lupus erythematosus. A comparison of three ethnic groups. Arthritis and Rheumatism 2005; 52: 2774-82.

[76] Clouse MEB, Magder LS, Witter F, Petri M. Early risk factors for pregnancy loss in lupus. Obstetrics \& Gynecology 2006; 107: 293-9

[77] Male C, Foulon D, Hoogendoom H, Vegh P, Silverman E, David M, Mitchell L. Predictive value of persistent versus transient antiphospholipid subtypes for the risk of thrombotic events in pediatric patients with systemic lupus erythematosus. Blood 2005; 106: 4152-8. 
[78] Alfetra A, Vadacca M, Conti L, Galluzo S, Mitterhofer AP, Ferri GM, Del- Porto F, Caccavo D, Gandolfo GM, Amoroso A. Thrombosis in systemic lupus erythematosus: congenital and acquired risk factors. Arthritis and Rheumatism 2005; 53: 452-9

[79] Chen PP, Wu M, Hahn BH. Some antiphospholipid antibodies bind to various serine proteases in hemostasis and tip the balance toward hypercoagulant states. Lupus 2010 19: 365

[80] Mackworth-Young CG. Antiphospholipid syndrome: multiple mechanisms. Clin Exp Immunol 2004; 136: 393-401.

[81] Mehdi AA, Uthman I, and Khamashta M. Antiphospholipid syndrome: pathogenesis and a window of treatment opportunities in the future. Eur J Clin Invest 2010; 40 (5): $451-464$

[82] Adams MJ, Palatinus AA, Harvey AM, and Khalafallah AA. Impaired control of the tissue factor pathway of blood coagulation in systemic lupus erythematosus. Lupus 2011 20: 1474

[83] Tripodi A, deGroot PG, and Pengo V. Antiphospholipid syndrome: laboratory detection,mechanisms of action and treatment. J Intern Med 2011; 270: 110-122.

[84] van Os GMA, Urbanus RT, Aga, C, Meijers JCM, and de Groot PG. Antiphospholipid syndrome:Current insights into laboratory diagnosis and Pathophysiology. Hämostaseologie 2010; 30: 139-143

[85] Matsuura E, Shen L, Matsunami Y, Quan N, Makarova M, Geske FJ, Boisen M, Yasuda S, Kobayashi K, and Lopez LR. Pathophysiology of b2-glycoprotein I in antiphospholipid syndrome. Lupus 2010 19: 379

[86] Devreese KMJ, Standardization of antiphospholipid antibody assays. Where do we stand? Lupus 2012 21: 718

[87] Devreese K, Hoylaerts MF. Challenges in the Diagnosis of the Antiphospholipid Syndrome. Clinical Chemistry 56:6; 930-940 (2010)

[88] RAS Roubey. Risky business: the interpretation, use, and abuse of antiphospholipid antibody tests in clinical practice. Lupus 2010 19: 440

[89] Pengo V, Denas G, Banzato A, Bison E, Bracco A, Visentin MS, Hoxha A, and Ruffatti A. Interpretation of laboratory data and need for reference laboratories. Lupus 2012 21: 732

[90] Bertolaccini ML, Amengual O, Atsumi T, Binder WL, de Laat B, Forastiero R, Kutteh WH, Lambert M, Matsubayashi H, Murthy V, Petri M, Rand JH, Sanmarco M, Tebo $\mathrm{AE}$, and Pierangeli SS. 'Non-criteria' aPL tests: report of a task force and preconference workshop at the 13th International Congress on Antiphospholipid Antibodies, Galveston, TX, USA, April 2010. Lupus 2011 20: 191 
[91] Pierangeli SS, Harris EN. A protocol for determination of anticardiolipin antibodies by ELISA. Nat P rotoc 2008;3:840-8.

[92] Petri M, Roubenoff R, Dallal G, Nadeau MR, Selhub J, Rosenberg IH. Plasma homocysteine as a risk factor for atherothrombotic events in systemic lupus erythematosus. The Lancet 1996; 348: 1120-4.

[93] Martínez-Berriotxoa A, Ruiz-Irastorza G, Egurbide MV, Rueda M, Aguirre C. Homocysteine, antiphospholipid antibodies and risk of thrombosis in patients with systemic lupus erythematosus. Lupus. 2004;13(12):927-33.

[94] Barcat D, Guérin V, Ryman A, Constans J, Vernhes JP, Vergnes C, Bonnet F, Delbrel $\mathrm{X}$, Morlat P, Longy-Boursier M, Conri C. Thrombophilia and thrombosis in systemic lupus erythematosus: a case-control study. Ann Rheum Dis. 2003 Oct;62(10):1016-7

[95] Vaya A, Calvo J, Alcala C, Mico L, Todol J, Ricart JM. Rheological alterations and thrombotic events in patients with systemic lupus erythematosus. Clinical Hemorhology and Microcirculation: 51; 2012: 51-58

[96] Kaiser R, Li Y, Chang M, Catanese J, Begovich AB, Brown EE, Edberg JC, McGwin Jr. G, Alarcon GS, Ramsey-Goldman R, Reville JD, Vila LM, Petri MA, Kimberly RP, Kimberly ET and Criswell LA. Genetic Risk Factors for Thrombosis in Systemic Lupus Erythematosus. J Rheumatol 2012;39:1603-10

[97] Demerci FYK, Dressen AS, Kammerer CM, Barmada MM, Kao AH, Ramsey-Goldman R, Manzi S, Kamboh MI. Functional Polymorphisms of the Coagulation Factor II Gene (F2) and Susceptibility to Systemic Lupus Erythematosus. The Journal of Rheumatology 2011; 38:4

[98] Terue, R, Perez-Sanchez C, Corral J, Merranz MT, Perez-Andreu V, Salz E, GarciaBarbera N, Martinez-Martinez I, Roldan V, Vicente V, Lopez-Pedrera C, Martinez C. Identification of miRNAs as potential modulators of tissue factor expression in patients with systemic lupus erythematosus and antiphospholipid syndrome. Journal of Thrombosis and Haemostasis; 9: 1985-1992.

[99] Bicakcigil M, Tasan DA, Tasdelen N, Mutlu N, and Yavuz S. Role of fibrinolytic parameters and plasminogen activator inhibitor 1 (PAI-1) promoter polymorphism on premature atherosclerosis in SLE patients. Lupus 2011 20: 1063

[100] Gong R, Liu Z, and Li L. Epistatic Effect of Plasminogen Activator Inhibitor 1and Fibrinogen Genes on Risk of Glomerular Microthrombosis in Lupus Nephritis. Arthritis \& Rheumatism 200756 (5); 1608-1617

[101] Ta'ssies D, Espinosa G, Munoz-Rodriguez FJ, Freire C, Cervera R, Monteagudo J, Maragall S, Escolar G, Ingelmo M, Ordinas A, Font J, and Reverter JC.The 4G/5G polymorphism of the type 1 plasminogen activator inhibitor gene and thrombosis in patients with antiphospholipid syndrome. Arthritis \& Rheumatism 2000;43(10):23492358 
[102] Pereira J, Alfaro G, Goycoolea M, Quiroga T, Ocqueteau M, Massardo L, Perez C, Saez C, Panes O, Matus V, Mezzano D. Circulating platelet -derived microparticles in systemic lupus erythematosus. Association with increased thrombin generation and procoagulant state. Thromb Haemost 2006; 95: 94-9.

[103] Nojima J,Juratsune H, Suehisa E, Kitani T, Iwatani Y, Kanakura Y. Strong correlation between the prevalence of cerebral infarction and the presence of anti-cardiolipin/ beta2-glycoprotein I and antiphosphatidylserine/prothrombin antibodies-Co-existance of these antibodies enhances ADP-induced platelet activation in vitro. Thromb Haemost 2004; 91: 967-76.

[104] Ekdahl KN, Bengtsson AA, Andersson J, Elgue G, Ronnblom L, Sturfelt G, Nilsson B. Thrombotic disease in systemic lupus erythematosus is associated with a maintained systemic platelet activation. Br J Haematol 2004; 125: 74-8.

[105] Levy Y, Shenkman B, Tamarin I, Pauzner R, Shoenfeld Y, Langevitz P, Savion N, Varon D. Increased platelet deposition on extracellular matrix under flow conditions in patients with antiphospholipid syndrome who experience thrombotic events. Arthritis and Rheumatism 2005; 52: 4011-17.

[106] Joseph JE, Harrison P, Mackie IJ, Isenberg DA, Machin SJ. Increased circulating platelet-leukocyte complexes and platelet activation in patients with antiphospholipid syndrome, systemic lupus erythematosus, and rheumatoid arthritis. Br J Haematol 2001; 115: 451-9.

[107] Martinuzzo ME, Maclouf J, Carreras LO, Levy-Toledano S. Antiphospholipid antibodies enhance thrombin-induced platelet activation and thromboxane formation. Thromb Haemost 1993; 70: 667-71.

[108] Vazques-Mellado J, Llorente L, Richaud-Patin Y, Alarcon-Segovia D. Exposure of anionic phospholipids upon platelet activation permits binding of $\beta 2$ glycoprotein I and through it that of IgG antiphospholipid antibodies: studies in platelets from patients with antiphospholipid syndrome and normal subjects. J Autoimmun 1994; 7: $335-48$.

[109] Frenkel EP, Mammen EF. Sticky platelet syndrome and thrombocythemia. Hematol Oncol Clin North Am. 2003 Feb;17(1):63-83.

[110] Mammen EF Sticky platelet syndrome.Semin Thromb Hemost. 1999;25(4):361-5.

[111] Mammen EF, Barnhart MI, Selik NR, Gilroy J, Klepach GL. Sticky platelet syndrome": a congenital platelet abnormality predisposing to thrombosis? Folia Haematol Int Mag Klin Morphol Blutforsch. 1988;115(3):361-5.

[112] Bick RL. Recurrent miscarriage syndrome due to blood coagulation protein/platelet defects: prevalence, treatment and outcome results. DRW Metroplex Recurrent Miscarriage Syndrome Cooperative Group.Clin Appl Thromb Hemost. 2000 Jul;6(3): $115-25$. 
[113] Weber M, Gerdsen F, Gutensohn K, Schoder V, Eifrig B, Hossfeld DK. Enhanced platelet aggregation with TRAP-6 and collagen in platelet aggregometry in patients with venous thromboembolism.Thromb Res. 2002 Sep 15;107(6):325-8.

[114] Joseph JE, Harrison P, Mackie IJ, Machin SJ.Platelet activation markers and the primary antiphospholipid syndrome (PAPS).Lupus. 1998;7 Suppl 2:S48-51. Review.

[115] Nojima J, Suehisa E, Kuratsune H, Machii T, Koike T, Kitani T, Kanakura Y, Amino N.Platelet activation induced by combined effects of anticardiolipin and lupus anticoagulant IgG antibodies in patients with systemic lupus erythematosus--possible association with thrombotic and thrombocytopenic complications. Thromb Haemost. 1999 Mar;81(3):436-41.

[116] Ekdahl KN, Bengtsson AA, Andersson J, Elgue G, Rönnblom L, Sturfelt G, Nilsson B.Thrombotic disease in systemic lupus erythematosus is associated with a maintained systemic platelet activation.Br J Haematol. 2004 Apr;125(1):74-8.

[117] Urbanus RT, de Laat HB, de Groot PG, Derksen HWM. Prolonged bleeding time and lupus anticoagulant. A second paradox in the anti phospholipid syndrome. Arthritis \& Rheumatism 2004; 50: 3605-9

[118] Miyakis S, Lockshin MD, Atsumi D, Branch DW, Brey RL, Cervera R, et al. International consensus statement on an update of the classification criteria for definite antiphospholipid syndrome (APS). J Thromb Haemost 2006;4:295-306.

[119] Bertero MT. Primary prevention in antiphospholipid antibody carriers. Lupus 2012; 21:751

[120] Ruiz-Irastorza G, Cuadrado MJ, Ruiz-Arruza I, et al. Evidence-based recommendations for the prevention and long-term management of thrombosis in antiphospholipid antibody-positive patients: report of a task force at the 13th International Congress on antiphospholipid antibodies. Lupus 2011; 20: 206-218.

[121] Sangle NA, Kristi J, Smock KJ. Antiphospholipid Antibody Syndrome. Arch Pathol Lab Med. 2011;135:1092-1096

[122] Bertsias G, Ioannidis JP, Boletis J, Bombardieri S, Cervera R, Dostal 28 C, et al. EULAR recommendations for the management of systemic lupus erythematosus. Report of a task force of the EULAR Standing Committee for International Clinical Studies Including Therapeutics. Ann Rheum Dis 2008;67:195-205.

[123] Ortel TL. Antiphospholipid syndrome: Laboratory testing and diagnostic strategies. Am. J. Hematol. 2012:87:S75-S81

[124] Tincani A, Andreoli L, Casu C, Cattaneo R, and Meroni P. Antiphospholipid antibody profile: implications for the evaluation and management of patients. Lupus 2010 19: 432 
[125] Branch DW, Khamashta MA. Antiphospholipid syndrome: obstetric diagnosis, management, and controversies. Obstet Gynecol. 2003;101(6):1333-1344.

[126] Kutteh WH. Antiphospholipid antibody-associated recurrent pregnancy loss: treatment with heparin and low-dose aspirin is superior to low-dose aspirin alone. Am J Obstet Gynecol 1996;174:1584-9.

[127] Tincani A, Branch W, Levy RA et al. Treatment of pregnant patients with antiphospholipid syndrome.Lupus2003;12:524-9.

[128] Ruiz-Irastorza G,Khamashta MA. Management of thrombosis in antiphospholipid syndrome and systemic lupus erythematosus in pregnancy. Ann NY Acad Sci 2005; 1051:606-12. 